\title{
ANALYSIS OF MOISTURE EVAPORATION FROM UNDERWEAR DESIGNED FOR FIRE-FIGHTERS
}

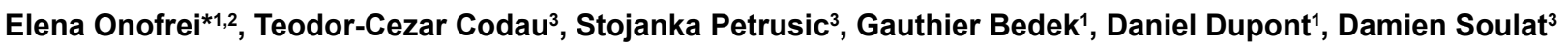 \\ ${ }^{1}$ GEMTEX, HEI, Université Catholique de Lille, Lille, F-59046, France \\ ${ }^{2}$ Technical University "Gheorghe Asachi" of lasi, lasi, 700050, Romania \\ ${ }^{3}$ GEMTEX, ENSAIT, Université Lille Nord de France, Roubaix, F-59056, France \\ eonofrei@yahoo.com, elena.onofrei@hei.fr
}

\begin{abstract}
:
In this study we analysed the effect of moisture on the thermal protective performance of fire-fighter clothing in case of routine fire-fighting conditions. In the first stage of this research we investigated simultaneous heat and moisture transfer through a single-layer fabric, used as underwear for fire-fighters, at different moisture conditions. In the second stage of the study, the underwear in dry and wet state was tested together with protective clothing systems for fire-fighter consisting of three or four layers. It was found that during the evaporation of the moisture, a temperature plateau appeared during which temperatures hardly rose. The energy consumption used for the phase change of moisture located in the assembly dominated the heat transfer process as long as there was moisture present. As soon as all water had evaporated, the temperatures approached the temperatures measured for dry samples. The moisture within the clothing assembly did not lead to increased temperatures compared with the measurements with dry samples. This research has confirmed that moisture can positively affect the thermal protection of a clothing system.
\end{abstract}

\section{Keywords:}

heat transfer, moisture transport, protective clothing, thermal comfort

\section{Introduction}

Thermal comfort is the key factor to be considered in clothing design, and furthermore a crucial factor for protective clothing systems for fire-fighters working in hot environments. Comfort researchers recognise that clothing comfort has two main aspects that combine to create a subjective perception of satisfactory performance. These are thermo-physiological and sensorial comfort. The moisture transmission behaviour of a clothing assembly plays a very important role in influencing its efficiency with respect to both thermo-physiological and sensorial body comfort [1].

Thermo-physiological comfort has two distinct phases. During normal wear, insensible perspiration is continuously generated by the body. Steady-state heat and moisture vapour fluxes are thus created and must be gradually dissipated to maintain thermoregulation and a feeling of thermal comfort. In transient wear conditions, characterised by intermittent pulses of moderate or heavy sweating caused by strenuous activity or climatic conditions, sensible perspiration and liquid sweat occur and must be rapidly managed by the clothing. Therefore, heat and moisture transfer properties under both steady and transient conditions must be considered for prediction of wearer comfort $[1,2]$.

Studies show that the maximum rate of sweat production by an average man is about $30 \mathrm{~g} / \mathrm{min}(1.8 \mathrm{l} / \mathrm{h})$ [3]. The sweat rate may even reach up to $4 \mathrm{l} / \mathrm{m}^{2}$ for shorter duration [4]. Schopper-Jochum et al. found that $30-44 \%$ of the sweated amount of moisture is accumulated in the clothing system [5]. Keiser C. and Rossi R.M. found that under usual fire-fighting circumstances, about two-thirds of this moisture may remain in the clothing system [6].

By analysing the moisture distribution in the different combinations of underwear with fire-fighter protective clothing, Mäkinen et al. observed that $50-80 \%$ of the sweat accumulated in the inner two layers [7]. Rossi $R$. found that $80 \%$ of the moisture remained in the inner two layers after 10 minutes sweating and still more than $60 \%$ after 20 minutes. Keiser $C$. made measurements on the sweating cylinder and discovered that over $90 \%$ of the moisture remained in the first three layers [4].

Studies on the influence of moisture in clothing system on the heat transfer suggest that moisture can inhibit or increase heat transfer through thermal protective material depending upon specific conditions. Chen investigated simultaneous heat and moisture transfer through single-layer cotton fabrics at different moisture conditions (dry, conditioned and moist) and for varying heat flux intensities $\left(21-188 \mathrm{~kW} / \mathrm{m}^{2}\right)$, for time exposure from 1 to 15 seconds. He found that at high heat exposures and for short test durations, moisture detrimentally affects thermal protection. For longer exposures, moisture can increase thermal protection [8]. Lee and Barker studied heat transfer through single-layered protective fabrics at $20 \mathrm{~W} / \mathrm{m}^{2}$ and $84 \mathrm{~W} / \mathrm{m}^{2}$ radiant heat exposures. Three different moisture conditions were used in their study: dry, conditioned and wet, at moisture loads ranging from $60 \%$ to $80 \%$. These tests 
showed that at high radiant exposure $\left(84 \mathrm{~W} / \mathrm{m}^{2}\right)$, the thermal protective performance of the fabric is reduced by up to $35 \%$. At incident heat flux level of $20 \mathrm{~W} / \mathrm{m}^{2}$, the thermal protection of wet samples increases [9]. Mäkinen et al. studied the effect of moisture content in underwear on thermal protection. The garments (layers moistened with different amounts of water) were exposed to a source of radiant heat of $20 \mathrm{~W} / \mathrm{m}^{2}$ according to the standard ISO 6942. They found that humidity in underwear decreased time to pain and time to burn, with the shortest burn time occurring at a moisture content of 30 $40 \%$. These data were obtained on systems without a moisture barrier [7]. Rossi and Zimmerli investigated the influence of humidity on the protective clothing during exposure to a radiant heat of $80 \mathrm{~W} / \mathrm{m}^{2}$ and $5 \mathrm{~W} / \mathrm{m}^{2}$, respectively. They found that at low radiant heat flux exposures, humidity in the inner clothing layers generally decreases the time to pain and the time to burn [10].

These contradictory results can be attributed to the different factors that influence heat transfer in protective clothing: the amount, the location and the transfer of the moisture, the type and conditioning of materials and the duration and intensity of thermal exposure [6].

According to Mäkinen [11], thermal environments are divided into three categories: routine, corresponding to a common intervention for firefighters characterised by low radiant heat flux from 0.42 to $1.26 \mathrm{~kW} / \mathrm{m}^{2}$ and air temperatures in the range of $10-60^{\circ} \mathrm{C}$; hazardous, representing an intervention in the presence of high radiant heat flux from 1.26 to $8.37 \mathrm{~kW} / \mathrm{m}^{2}$ and air temperatures in the range of $60-300^{\circ} \mathrm{C}$; and emergency corresponding to extreme conditions from 8.37 to $125.6 \mathrm{~kW} / \mathrm{m}^{2}$ and air temperatures in the range of $300-1000^{\circ} \mathrm{C}$.

Data obtained over the years show that most burn injuries sustained by fire-fighters occurred in thermal environments with low radiation level (classified as routine or hazardous conditions), as a result of prolonged exposure [12-14]. So far, almost all the studies on thermal protective performance were conducted for high-level radiant heat flux corresponding to the emergency conditions; only a few studies have been conducted on thermal protective performance with prolonged exposure to hazardous conditions; and no studies have been found for the moisture influence on heat transfer through thermal protective clothing under routine conditions.

Thus, a research was started to study the effect of moisture on the thermal protective performance of fire-fighter clothing in lowlevel radiant heat environment, the most common conditions in which the fire-fighters work. Understanding mechanisms by which moisture in textiles affects heat transfer through clothing systems could lead to improvements in the design of thermal protective clothing [15].

The problem of vapour diffusion through the layers of the protective clothing is complicated and has to be approached through the integration of the interaction between heat and mass transfer and heat of phase changes [4]. Therefore, in the first stage of this research moisture effect on heat transfer through single-layer fabrics was studied. We investigated simultaneous heat and moisture transfer through a single-layer fabric, used as underwear for fire-fighters, at different moisture conditions, in the case of routine firefighting operation (radiant heat flux of $1100 \mathrm{~W} / \mathrm{m}^{2}$ ).

In the second stage of the study, the underwear in dry and wet state was tested together with protective clothing systems for a fire-fighter consisting of three and four layers.

For the wet tests, at the beginning of the experiments, the underwear was wetted only with defined amounts of water, in order to simulate the accumulation of sweat in this layer. The moisture membrane prevents the passage of liquid water from underwear to outer layers, and the water-vapour diffusion will occur only through the layers of protective system.

\section{Experimental}

\subsection{Materials}

Protective clothing systems consisting of three and four aramidbased layers which are typical in the underwear designed for fire-fighters:

- Outer layer - which protects against all kinds of thermal hazards and mechanical impact;

- Moisture barrier - which protects against water and other fluids;

- Thermal barrier - which is an insulating layer which protects against heat; and

- Inner layer - which protects the thermal barrier against abrasion.

Two multi-layer fire-fighter jackets were chosen for analysis. The first assembly was composed of outer shell, moisture barrier and thermal barrier, respectively. The moisture barrier is a hydrophilic polyurethane (PU) membrane. The second one contains outer shell, moisture barrier, thermal barrier and inner layer. The moisture barrier is based on the microporous hydrophobic polytetrafluoroethylene (PTFE) membrane.

In firefighting, underwear's principal role is to provide an additional layer of material between the hazard (radiant or direct flame contact) and the person's skin. Cotton is the most commonly used underwear, but wool, silk, aramid or other flame-resistant materials are also used [16]. Fabrics made by synthetic fibres, $100 \%$ or blended with natural fibres, resistant to high temperatures as well as to chemical agents are used for underwear for firemen, due to their improved ability to remove moisture, which seemingly could improve fire-fighters' comfort and might increase efficiency. In this study, underwear made of functionalised polyamide base fibres, resistant to high temperatures as well as to chemical agents and with good moisture management capacity, was used.

The physical properties (thickness, surface weight, bulk density) and the thermo-physical properties (water-vapour resistance and thermal resistance) of the fabrics were measured and are displayed in Table 1. 
Table 1. Physical and thermo-physical properties of the fabrics

\begin{tabular}{|c|c|c|c|c|c|c|}
\hline & Material & $\begin{array}{c}\text { Surface } \\
\text { weight, } g / m^{2}\end{array}$ & $\begin{array}{c}\text { Thickness, } \\
\text { mm }\end{array}$ & $\begin{array}{c}\text { Density, } \\
\mathrm{kg} / \mathrm{m}^{3}\end{array}$ & $\begin{array}{c}\text { Rct } \\
\mathrm{m}^{2} \mathrm{~K} / \mathrm{W}\end{array}$ & $\begin{array}{c}\text { Ret } \\
\mathrm{m}^{2} \mathrm{~Pa} / \mathrm{W}\end{array}$ \\
\hline $\begin{array}{l}\text { Underwear } \\
\text { (UW) }\end{array}$ & $\begin{array}{c}\text { Functionalised polyamide } \\
\text { base } \\
\text { knitted -piqué }\end{array}$ & $283 \pm 4$ & $1.19 \pm 0.01$ & $238 \pm 4$ & $0.0281 \pm 0.0003$ & $4.08 \pm 0.03$ \\
\hline \multicolumn{7}{|c|}{ Fire-fighter Jackets } \\
\hline \multicolumn{2}{|c|}{ Fire-fighter Jacket 1 (FJ1) } & $540 \pm 4$ & $2.40 \pm 0.04$ & $224 \pm 5$ & $0.0938 \pm 0.0048$ & $34.95 \pm 0.04$ \\
\hline Outer shell & $100 \%$ aramid woven & $242 \pm 2$ & $0.5 \pm 0.01$ & $489 \pm 5$ & $0.0129 \pm 0.0006$ & $5.76 \pm 0.27$ \\
\hline $\begin{array}{l}\text { Thermal } \\
\text { liner }\end{array}$ & $100 \%$ aramid non-woven & $98 \pm 2$ & $1.46 \pm 0.03$ & $67 \pm 2$ & $0.0689 \pm 0.0034$ & $6.64 \pm 0.21$ \\
\hline $\begin{array}{l}\text { Moisture } \\
\text { barrier }\end{array}$ & $\begin{array}{l}\text { polyurethane coated } 100 \% \\
\text { aramid } \\
\text { knitted (coated) }\end{array}$ & $195 \pm 2$ & $0.47 \pm 0.00$ & $418 \pm 6$ & $0.0134 \pm 0.0034$ & $30.16 \pm 0.02$ \\
\hline \multicolumn{2}{|c|}{ Fire-fighter Jacket 2 (FJ2) } & $570 \pm 4$ & $2.13 \pm 0.03$ & $267 \pm 4$ & $0.0715 \pm 0.0023$ & $25.27 \pm 0.91$ \\
\hline Outer shell & $100 \%$ aramid woven & $242 \pm 2$ & $0.5 \pm 0.01$ & $489 \pm 5$ & $0.0129 \pm 0.0006$ & $5.76 \pm 0.27$ \\
\hline $\begin{array}{l}\text { Thermal } \\
\text { liner }\end{array}$ & $\begin{array}{l}100 \% \text { aramid } \\
\text { non-woven }\end{array}$ & $49 \pm 2$ & $0.38 \pm 0.01$ & $127 \pm 3$ & $0.0147 \pm 0.0003$ & $1.93 \pm 0.00$ \\
\hline $\begin{array}{l}\text { Moisture } \\
\text { barrier }\end{array}$ & $\begin{array}{l}\text { PTFE membrane laminated } \\
\text { to } 100 \% \text { aramid non-woven }\end{array}$ & $128 \pm 3$ & $0.98 \pm 0.03$ & $131 \pm 5$ & $0.0263 \pm 0.0008$ & $7.27 \pm 0.03$ \\
\hline Inner layer & $100 \%$ aramid woven & $150 \pm 1$ & $0.37 \pm 0.00$ & $403 \pm 6$ & $0.0129 \pm 0.0003$ & $3.44 \pm 0.14$ \\
\hline
\end{tabular}

Thickness was measured under the pressure of $1 \pm 0.01$ $\mathrm{kPa}$, according to the standard ISO 5084:1996. Density was calculated from the values of fabric monolayer thickness and surface weight (which was determined using an analytical balance). The average of ten measurements was calculated.

Measurements of thermal $\left(R_{c t}\right)$ and water-vapour resistance $\left(R_{e t}\right)$ of mono- and multi-layer fabrics were carried out on the sweating-guarded hotplate according to the standard ISO 11092:1993 [17]. Specific environment testing conditions prescribed by this standard were met using a climatic chamber.

It can be noted that the sum of $R_{c t}$ values of individual layers is close to the measured $R_{c t}$ of the assembly composed of the corresponding layers. In contrast with the thermal resistance, the total water-vapour resistance of a combination of textiles is not always equal to the sum of the single resistances. In particular, the inclusion of hydrophilic components imparts the complexity of the phenomenon, as the water-vapour resistance of these materials depends on the relative humidity of the membrane [18].

\subsection{Experimental set-up and procedure}

\subsubsection{The test apparatus}

The scheme of the test apparatus for determining heat and moisture transfer under both steady and transient conditions through single-layer or multi-layer fabrics, when exposed to a low-level radiant heat flux, is shown in Figure 1.

An infrared lamp (SICCA RED 150W 240V HG) was used as radiant heat source in order to supply a constant radiant heat flux at the surface of the sample corresponding to the routine condition of the firefighting environment. Figure 2 shows the relative intensity distribution of the lamp [19].

For every Watt electrical power, the radiant intensity is expressed by the equation (1):

$$
I=\frac{P}{\Omega}
$$

$\mathrm{P}$ - the power source, $\mathrm{W}$

I - the radiant intensity, W/Sr

$\Omega$ - the solid angle, $\mathrm{Sr}$.

$$
\Omega=\frac{S}{r^{2}}
$$

$\mathrm{S}$ - the limited area of the spherical zone of solid angle $\Omega, \mathrm{m}^{2}$ $r$ - the radius of the sphere, $m$.

Thus, from equations (1) and (2):

$$
I=\frac{P \times r^{2}}{S}
$$

or,

$$
\Phi=\frac{I}{r^{2}}
$$

where $F$ is the radiant heat flux density, $\mathrm{W} / \mathrm{m}^{2}$. 


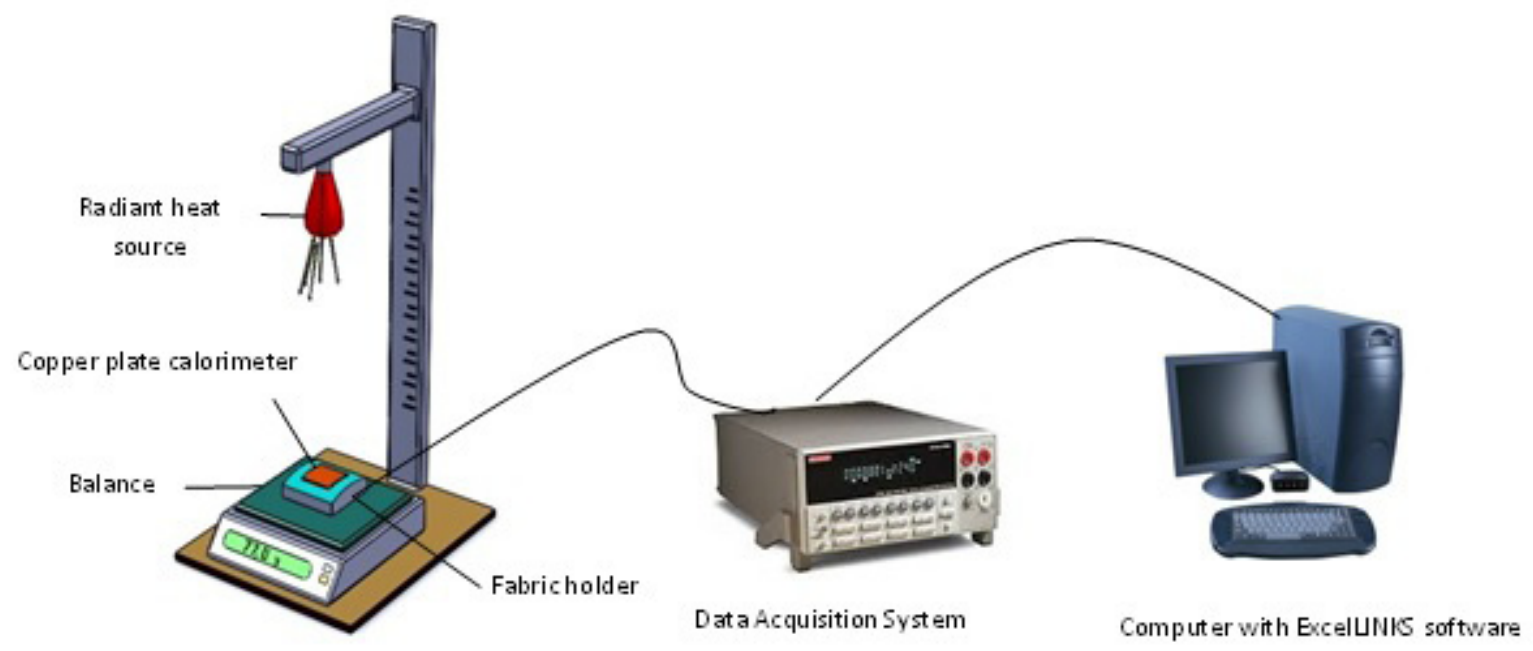

Figure 1. Configuration of the test apparatus for determining heat and moisture transfer through fabrics exposed to a low-level radiant heat flux

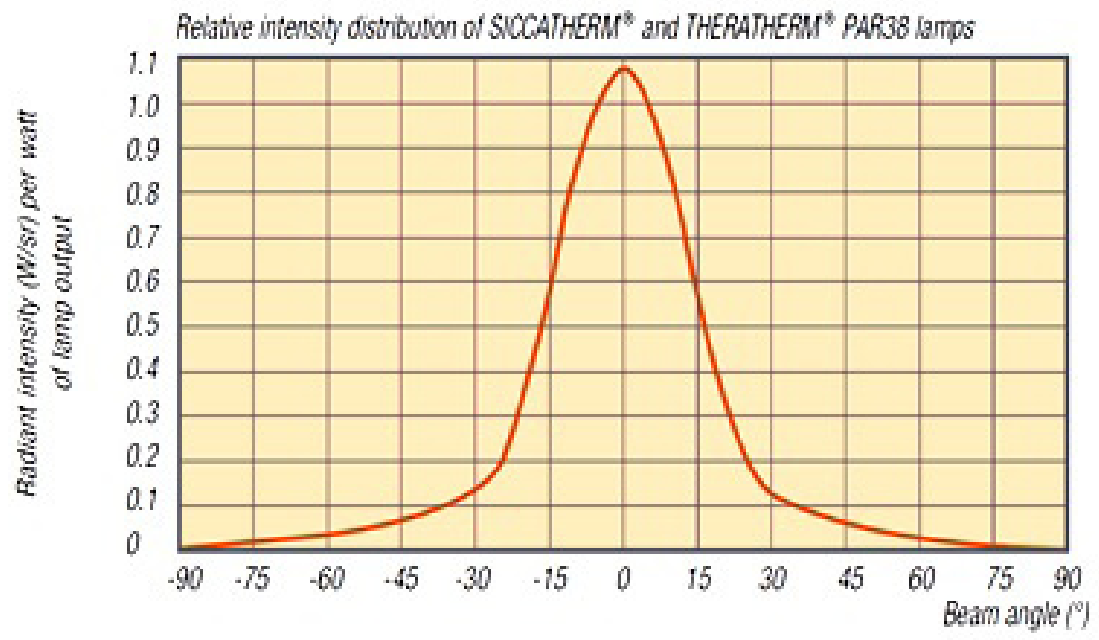

Figure 2. Relative intensity distribution of SICCATHERM ${ }^{\circledR}$ lamp

For small angles, the radius of the sphere can be approximated with the distance " $d$ " between the radiant source and calorimeter. In our arrangement, the maximum distance between the source and the calorimeter is $420 \mathrm{~mm}$. For this distance the beam angle value is between 0 and $3.6\left(^{\circ}\right)$ and the average intensity of the lamp is 1.01 [W/Sr]. For a radiant source of 150 [W] the minimum heat flux density is $852\left[\mathrm{~W} / \mathrm{m}^{2}\right]$.

The fabric holder assembly was fabricated to hold and position a fabric sample rigidly against the hot air impinging flow. The heat transferred across the fabric is measured with a sensor assembly positioned on the fabric holder. The fabric holder consists of $90 \times 90 \mathrm{~mm}$ square piece of extruded PVC board of nominal thickness $25 \mathrm{~mm}$ and known density and thermal characteristics.

The sensor assembly is composed of a copper plate calorimeter $50 \times 50 \mathrm{~mm}, 1.6 \mathrm{~mm}$ thick, an insulating board and a Chromega ${ }^{\mathrm{TM}}$ - Constantan thermocouple silver welded on the copper plate. The calorimeter face is painted with a flat black paint having a coefficient of absorption greater than 0.9 , so as to absorb radiant flux. The cooper plate is bent into an arc with a radius of $130 \mathrm{~mm}$. The copper plate is accurately weighed before assembly. The curved copper plate is bonded to the mounting block around its edges using an adhesive resistant to high temperature.

The fabric holder assembly is placed on the precise METTLER TOLEDO balance in order to register the evaporation rate. The data are collected and stored with the LabX direct Balance 2.3 system on a PC.

E-type Chromega ${ }^{\mathrm{TM}}$-Constantan thermocouples (Omega Engineering LTD, USA) are placed between fabric layers in order to measure the temperature distribution through the multi-layer assembly during experiments.

A Data Acquisition System Keithley 2700 with 20-Channel Differential with Multiplexer module 7700 coupled to a computer with ExceLINKS software has been used to register the data. 


\subsubsection{Calibration of the radiant source}

In the presented configuration, calibration of the test apparatus is performed as follows:

1. The test frame is positioned at a distance ' $d$ ', on the vertical central line of the radiant source.

2. The temperature measuring device is switched on.

3. The radiation source is switched on and allowed to heat the movable screen closed until the radiation is constant. The steady state is reached in about 30 seconds.

4. The movable screen is removed and returned to position after a temperature rise of about $12^{\circ} \mathrm{C}$ has been reached.

5. The recorded output shows a linear temperature/time relationship. From this linear region, the rate of the rise in temperature $\mathrm{R}$ is determined, expressed in ${ }^{\circ} \mathrm{C} / \mathrm{s}$.

6. The incident heat flux density, in $\mathrm{kW} / \mathrm{m}^{2}$, is then determined from the following equation:

$$
\mathrm{Q}_{0}=\frac{\mathrm{M} \cdot \mathrm{c}_{\mathrm{p}} \cdot \mathrm{R}}{\alpha \cdot \mathrm{A}}
$$

where:

$\mathrm{M}$ - the mass of cooper plate, $\mathrm{kg}$

$\mathrm{C}_{\mathrm{p}}$ - the specific heat of copper, $\mathrm{J} / \mathrm{kgK}$

$\mathrm{R}$ - the rate of rise in the calorimeter temperature in the linear region, ${ }^{\circ} \mathrm{C} / \mathrm{s}$

A - the area of copper plate, $\mathrm{m}^{2}$

a - the absorption coefficient of the painted surface of the calorimeter.

The incident heat flux density can be adjusted to the required level by varying the distance between the radiant source and the calorimeter.

The calibration of the radiant source is confirmed by measurements using an ultra-thin Heat Flow Meter $50 \times 50 \mathrm{~mm}$, from CAPTEC with a sensibility of $11.7 \mathrm{mV} /\left(\mathrm{W} / \mathrm{m}^{2}\right)$.

\subsubsection{Experiments}

\subsubsection{Single-layer tests}

The specimen had the dimension $(57.5 \times 57.5) \mathrm{mm}$. The distance between the infrared lamp and the outer surface was defined in order to supply a constant radiant heat flux of 1100 $\mathrm{W} / \mathrm{m}^{2}$ at the surface of the sample.

The experiment started by first applying the flux on a movable screen which was initially closed for 30 seconds to prevent premature heating of the fabric prior to testing. When the screen was quickly opened the heat flux reached the front fabric surface. The fabric sample was exposed to the heat flux until the steady state was reached.

Both dry and wet tests were performed. For the wet tests, at the beginning of the experiment the underwear was wetted with a defined amount of water $(1.08 \mathrm{~g}, 1.38 \mathrm{~g}$ and $1.74 \mathrm{~g})$. This corresponds to the moisture content of $120 \%, 160 \%$ and $200 \%$, respectively, for the underwear relative to the conditioned weight $\left(20{ }^{\circ} \mathrm{C}\right.$ and $\left.40 \% \mathrm{RH}\right)$. To moisten the sample, the following protocol was used: the specimen was first conditioned in the testing room prior to moisture application and testing. The sample was immersed in distilled water and then placed between sheets of rolled-over blotting paper using a metal roller for removing the excess water until the needed amount of water was obtained.

The testing conditions were constant during the experiments: ambient temperature $\mathrm{T}_{\text {amb }}=20^{\circ} \mathrm{C}$ and air relative humidity $\mathrm{RH}=$ $40 \%$.

\subsubsection{Multi-layer fabric system tests}

The same protocol was used for multi-layer fabric systems without additional water (dry condition) and with additional water within the underwear. The outer shell, thermal liner and moisture barrier and inner layer specimens have the dimension (70x70) $\mathrm{mm}$ and were fastened on the specimen holder using some clamps. A slight tensioning force of $2 \mathrm{~N}$ was applied in order to avoid the air gaps between layers. The underwear specimen had the dimension $(57.5 \times 57.5) \mathrm{mm}$.

For the wet tests, the underwear was wetted with the same amounts of water (1.08 g, $1.38 \mathrm{~g}$ and $1.78 \mathrm{~g}$ ), corresponding to the moisture content of $120 \%, 160 \%$ and $200 \%$, respectively, for the underwear.

E-type Chromega ${ }^{\mathrm{TM}}$-Constantan thermocouples (Omega Engineering LTD, USA) were placed between fabric layers in order to measure the temperature distribution (T1, T2 and T3) through the textile assembly during the experiment. The thermocouple accuracy was $0.3^{\circ} \mathrm{C}$, the response time $0.3 \mathrm{~s}$, wire diameter $0.075 \mathrm{~mm}$ and Teflon insulation $0.3 \mathrm{~mm}$.

The locations of thermocouples into the fabric systems are shown in Figure 3.

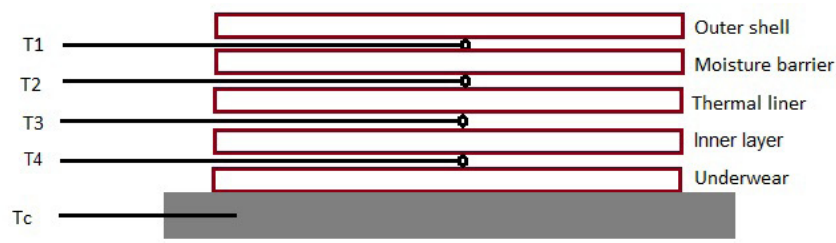

Figure 3. The thermocouples location 


\section{Results and Discussion}

\subsection{Single-underwear tests}

Figure 4 shows the temperature variation for the constant heat flux of $1100 \mathrm{~W} / \mathrm{m}^{2}$, for underwear with different moisture content. The temperature pattern for wetted fabrics can be divided into four different phases: an initial rising phase, a stagnation phase, a final rising phase and a final stagnation phase. During the first phase energy was used mainly in heating up the fabric and moisture, and only a small quantity of moisture was evaporated. During the second phase the temperature was constant $\left(43.5^{\circ} \mathrm{C}\right)$ regardless of the initial amount of water contained in the material. On the contrary, the amount of moisture had a significant influence on the second phase duration. Thus, for the $1.08 \mathrm{~g}$ moisture content $(120 \%)$ the temperature plateau was registered for 1398 seconds, for $1.38 \mathrm{~g}$ moisture content (160\%) for 1608 seconds and for $1.74 \mathrm{~g}$ moisture content $(200 \%)$ for 1956 seconds. Keiser C. [4] found a linear correlation between the amount of water and the duration of the second phase. This linear correlation was confirmed by our results (see Figure 5).
In the third phase the temperature started rising again, and the fourth phase represented the equilibrium.

The temperature was lower during evaporation of the moisture than during the measurement of the dry sample. The higher the initial moisture content the higher the difference during the evaporation. For all experiments, as soon as the moisture had evaporated, the temperature approached the temperatures measured for dry sample, $75^{\circ} \mathrm{C}$.

Figure 6 shows the decrease in the moisture contents.

The moisture content stayed constant at the beginning for about 30-60 seconds and then decreased. The moisture decreased linearly with time. From these results the evaporation rates were calculated by dividing the moisture content by the time it took to evaporate the amount of water. The evaporation rates were $0.981 \times 10^{-3} \mathrm{~g} / \mathrm{s}$ for $200 \%$ moisture content, $0.927 \times 10^{-3}$ $\mathrm{g} / \mathrm{s}$ for $160 \%$ moisture content and $0.841 \times 10^{-3} \mathrm{~g} / \mathrm{s}$ for $120 \%$ moisture content, respectively, that is, $0.297 \mathrm{~g} / \mathrm{m}^{2} . \mathrm{s}, 0.280 \mathrm{~g} /$ $\mathrm{m}^{2}$.s and $0.255 \mathrm{~g} / \mathrm{m}^{2} . \mathrm{s}$, respectively. Thus, for the same radiant heat flux, the rate of evaporation rate seemed to increase linearly with the moisture content (Figure 7).

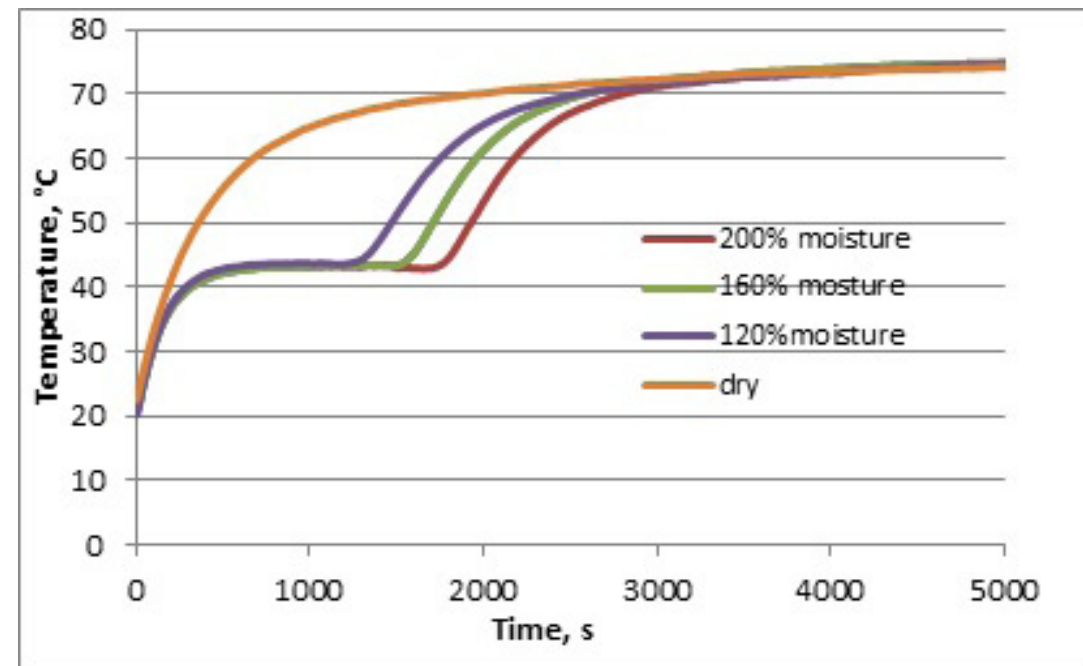

Figure 4. The temperature variation for constant heat flux of $1100 \mathrm{~W} / \mathrm{m}^{2}$, for underwear with different moisture content

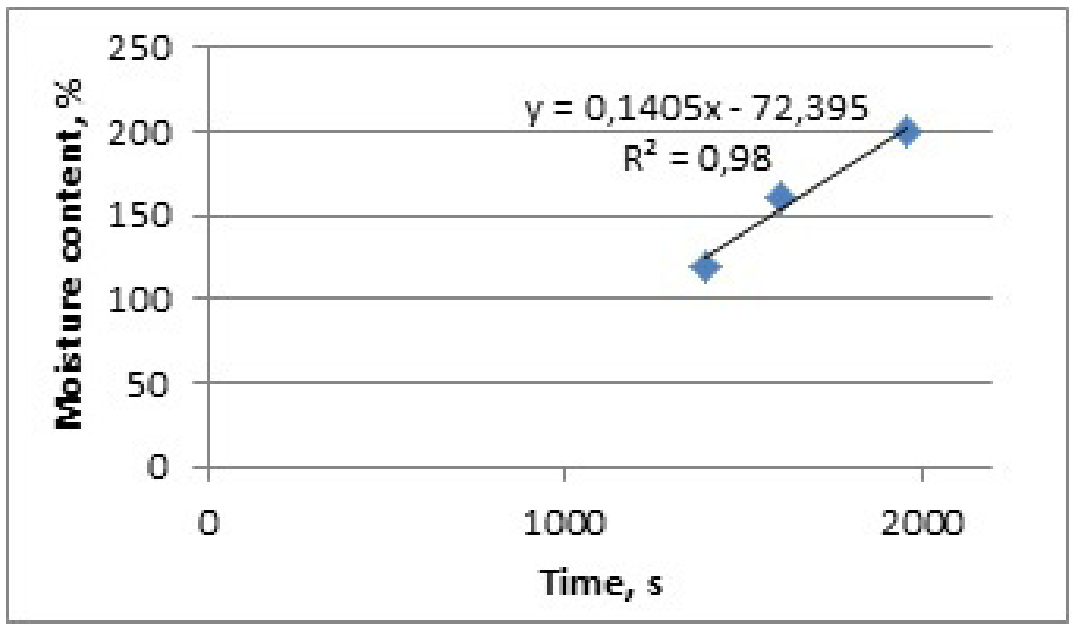

Figure 5. Correlation of the amount of water and the time at the end of phase two 


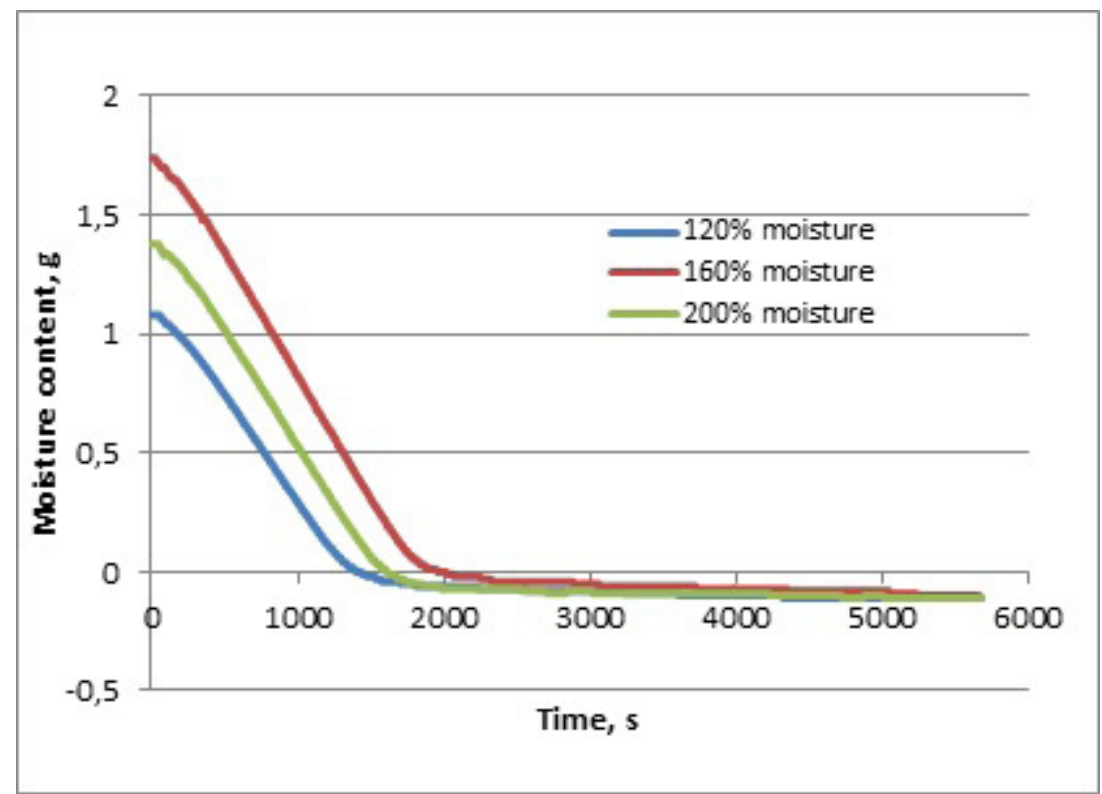

Figure 6. Variation of moisture content

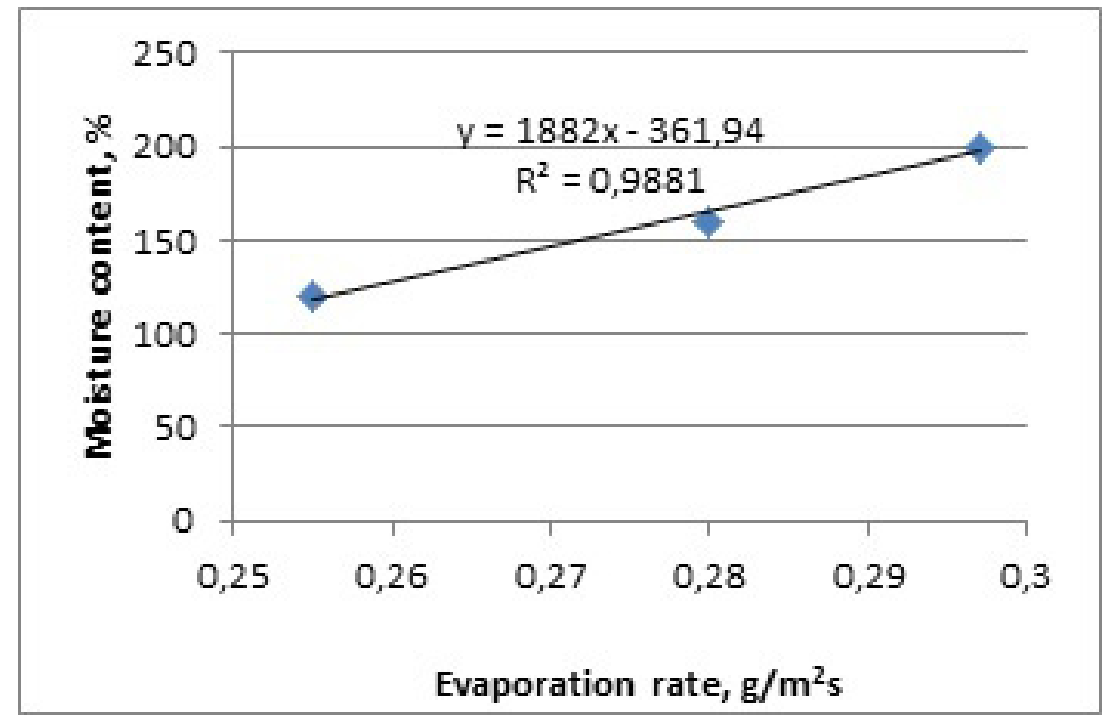

Figure 7. Correlation of the evaporation rate and the amount of moisture

At the end of the experiment, moisture content reached a negative value. As the weight of the whole system was set to zero initially, a negative amount of water at the end of measurement indicates that this amount of water must be present within the textile layer at the beginning of the measurement. The samples were kept at room condition prior to the tests, and therefore an initial amount of water corresponding to their moisture regain was present in the material. After radiation was cut off, the same amount of water was absorbed back into the fabric from the surrounding atmosphere. This amount represents $12.79 \%$ of the mass of perfectly dry material and corresponds to the moisture regain of fibres, that is, $12 \%$.

The energy used for evaporation can be calculated from

where

$$
Q_{\text {evap }}=\dot{\mathrm{m}}_{\text {evap }} \cdot \varphi_{\text {evap }}\left(\mathrm{W} / \mathrm{m}^{2}\right)
$$

$\mathrm{m}_{\text {evap }}$ is the evaporative mass flux, $\mathrm{kg} / \mathrm{m}^{2} \mathrm{~s}$

$\varphi_{\text {evap }}$ is the latent heat of evaporation, $\mathrm{J} / \mathrm{kg}$.
Considering that the temperature of the system remains constant during evaporation, we can calculate the energy used for evaporation:

$$
Q_{\text {evap }}=Q_{\text {in }}-Q_{\text {rad-out }}-Q_{\text {conv }}\left(W / m^{2}\right)
$$

The general inward heat flux $Q_{\text {in }}\left(W / m^{2}\right)$ represents a heat flux that enters into domain.

$$
Q_{\text {in }}=\varepsilon Q\left(W / m^{2}\right)
$$

$\varepsilon$ is the emissivity of the fabric

$Q$ is the radiant heat flux, $\mathrm{W} / \mathrm{m}^{2}$.

The emitted thermal radiate heat flow is defined as

$$
\mathrm{Q}_{\text {rad-out }}=\varepsilon \sigma\left(\mathrm{T}_{\text {surf }}^{4}-\mathrm{T}_{\mathrm{amb}}^{4}\right)\left(\mathrm{W} / \mathrm{m}^{2}\right)
$$


where

$\varepsilon$ is the emissivity of the fabric

$\sigma$ is the Stefan-Boltzmann constant, $\mathrm{W} / \mathrm{m}^{2} \mathrm{~K}^{4}$

$\mathrm{T}_{\text {surf }}$ is the surface temperature, $\mathrm{K}$

$\mathrm{T}_{\text {amb }}$ is the ambient temperature, $\mathrm{K}$.

Natural convection heat transfer following the temperature gradient between the surface and the environment occurs:

$$
\mathrm{Q}_{\text {conv }}=\mathrm{h}_{\mathrm{c}}\left(\mathrm{T}_{\text {surf }}-\mathrm{T}_{\mathrm{amb}}\right)
$$

$\left(\mathrm{W} / \mathrm{m}^{2}\right)$

where $h_{c}$ is the natural convection heat transfer coefficient $\left(\mathrm{W} / \mathrm{m}^{2} \mathrm{~K}\right)$ calculated using the definition of the Nusselt number:

$$
\mathrm{h}_{\mathrm{c}}=\mathrm{Nu} \frac{\mathrm{k}_{\text {air }}}{\mathrm{L}} \quad\left(\mathrm{W} / \mathrm{m}^{2} \mathrm{~K}\right) \quad\left(\mathrm{W} / \mathrm{m}^{2} \mathrm{~K}\right)
$$

where

$\mathrm{Nu}$ is the Nusselt number

$\mathrm{k}_{\text {air }}$ is the thermal conductivity of the air $\mathrm{W} /(\mathrm{m} \cdot \mathrm{K})$

$L$ is the characteristic length, $m$.

According to the empirical correlation of free convection on a horizontal plate for $\mathrm{T}_{\text {surf }}>\mathrm{T}_{\mathrm{amb}}$ [20]:

$$
\begin{aligned}
& \mathrm{Nu}= \begin{cases}0.54 \mathrm{Ra}_{\mathrm{L}}^{1 / 4} & \mathrm{Ra}_{\mathrm{L}} \leq 10^{7} \\
0.15 \mathrm{Ra}_{\mathrm{L}}{ }^{1 / 3} & \mathrm{Ra}_{\mathrm{L}}>10^{7}\end{cases} \\
& \mathrm{Ra}_{\mathrm{L}}=\frac{\mathrm{g}|\partial \rho / \partial \mathrm{T}|_{\mathrm{p}} \cdot \rho \mathrm{C}_{\mathrm{p}} \cdot \Delta \mathrm{T} \cdot \mathrm{L}^{3}}{\mathrm{k} \mu}
\end{aligned}
$$

where

$\mathrm{g}$ is the acceleration of gravity, $\mathrm{m} / \mathrm{s}^{2}$

$\Delta T$ is the temperature difference between the surface and ambient conditions, $\mathrm{K}$

$\mathrm{k}$ is the thermal conductivity of the fluid $\mathrm{W} /(\mathrm{m} \cdot \mathrm{K})$

$\rho$ is the fluid density, $\mathrm{kg} / \mathrm{m}^{3}$

$\mathrm{C}_{\mathrm{p}}$ is the heat capacity of the fluid, $\mathrm{J} /(\mathrm{kg} \cdot \mathrm{K})$

$\mu$ is the dynamic viscosity, $\mathrm{Pa} \cdot \mathrm{S}$

$L$ is the characteristic length, $m$

$R a_{L}$ is the Rayleigh number.
The constants used for the calculation of the energy balance are shown in Table 2.

Table 2. Constants used for the calculation of the energy balance

\begin{tabular}{|c|c|c|}
\hline Constant & Value & Unit \\
\hline $\mathrm{Q}_{\text {in }}$ & 1100 & $\mathrm{~W} / \mathrm{m}^{2}$ \\
\hline $\mathrm{e}$ & 0.95 & - \\
\hline $\mathrm{T}_{\text {surf }}$ & 51 & ${ }^{\circ} \mathrm{C}$ \\
\hline $\mathrm{T}_{\text {amb }}$ & 20 & ${ }^{\circ} \mathrm{C}$ \\
\hline $\mathrm{h}_{\mathrm{c}}$ & 9.8 & $\mathrm{~W} / \mathrm{m}^{2} \mathrm{~K}$ \\
\hline $\mathrm{m}_{\text {evap }}$ & 0.280 & $\mathrm{~g} / \mathrm{m}^{2} \mathrm{~s}$ \\
\hline $\mathrm{j}_{\text {evap }}$ & 2257 & $\mathrm{~J} / \mathrm{g}$ \\
\hline
\end{tabular}

The heat of evaporation according to equation (6) is $632 \mathrm{~W} / \mathrm{m}^{2}$ and according to equation (7) is $600 \mathrm{~W} / \mathrm{m}^{2}$. Thus, a good correlation can be considered between the two values, taking into account the assumptions made.

\subsection{Fire-fighter Jackets + Underwear tests}

Figure 8 shows the evolution of temperature over time according to measurements at all the four interfaces, for the three-layer protective system with underwear, FJ1 +UW, in dry condition.

Figure 8 shows that the temperature of the thermocouples starts rising sharply from the moment the fabric system is exposed to the radiant flux at $\mathrm{t}=0$ and then gradually rises until stabilisation. The highest rate of rise is registered by $\mathrm{T} 1$ temperature and the smallest rate in temperature increase is registered by the calorimeter temperature, Tc. The energy is conducted to the copper plate interface, but in a relatively slower process that proves the thermal protective effect of the fabric system. The temperature at the back face stabilises at approximately $72{ }^{\circ} \mathrm{C}$, and the temperature $\mathrm{T} 1$ at about $95^{\circ} \mathrm{C}$.

Figures 9, 10 and 11 show the evolution of temperature over time according to measurements at all the four interfaces,

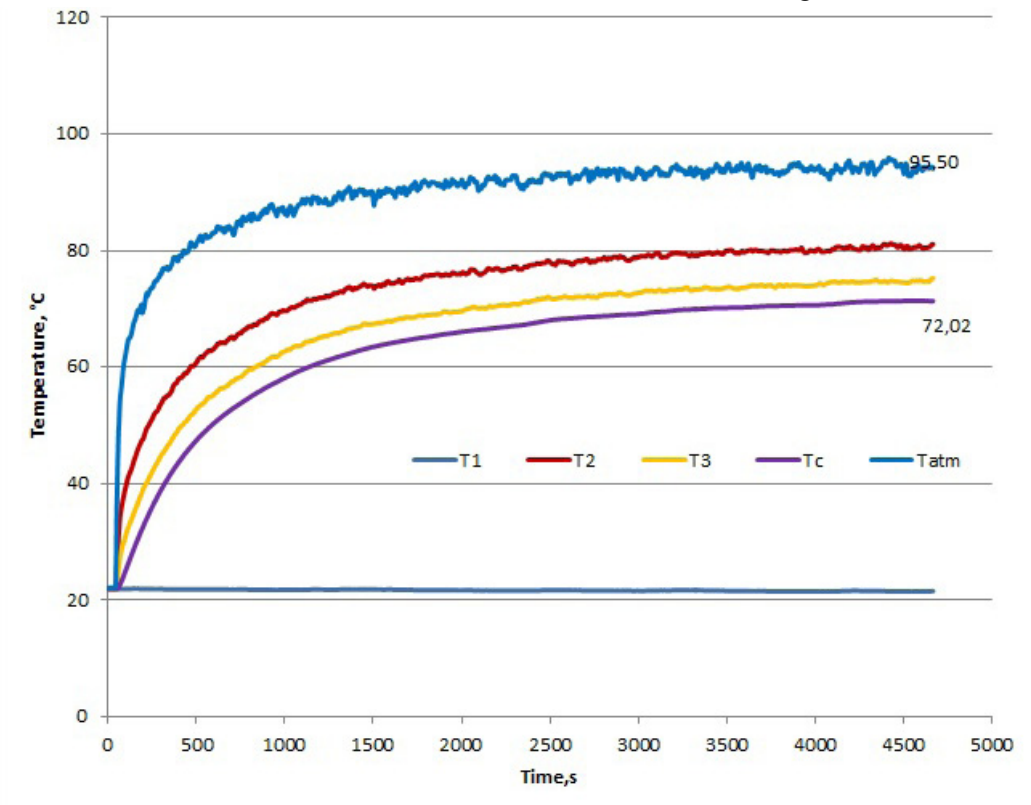

Figure 8. Temperature profiles with dry fabrics $(\mathrm{FJ} 1+\mathrm{UW})$ when exposed to a radiant heat flux of $1100 \mathrm{~W} / \mathrm{m}^{2}$ 


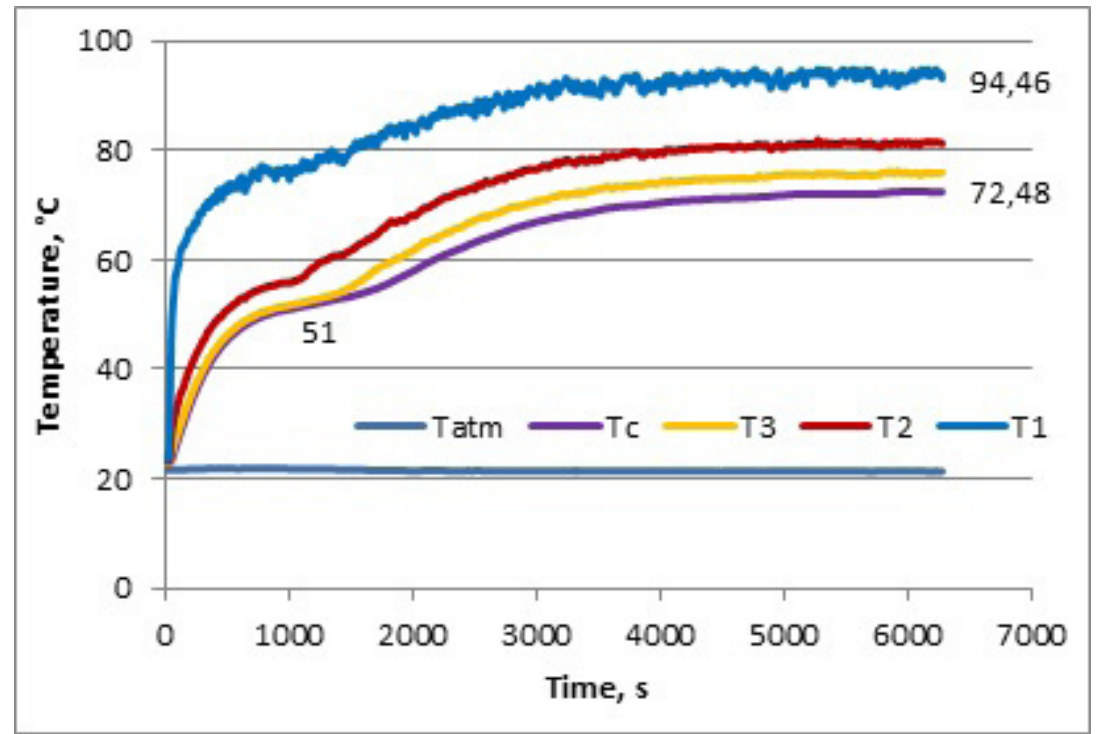

Figure 9. Temperatures between the layers $(\mathrm{FJ} 1+\mathrm{W})$ Moisture content $120 \%$, located in the underwear; heat flux $1100 \mathrm{~W} / \mathrm{m}^{2}$

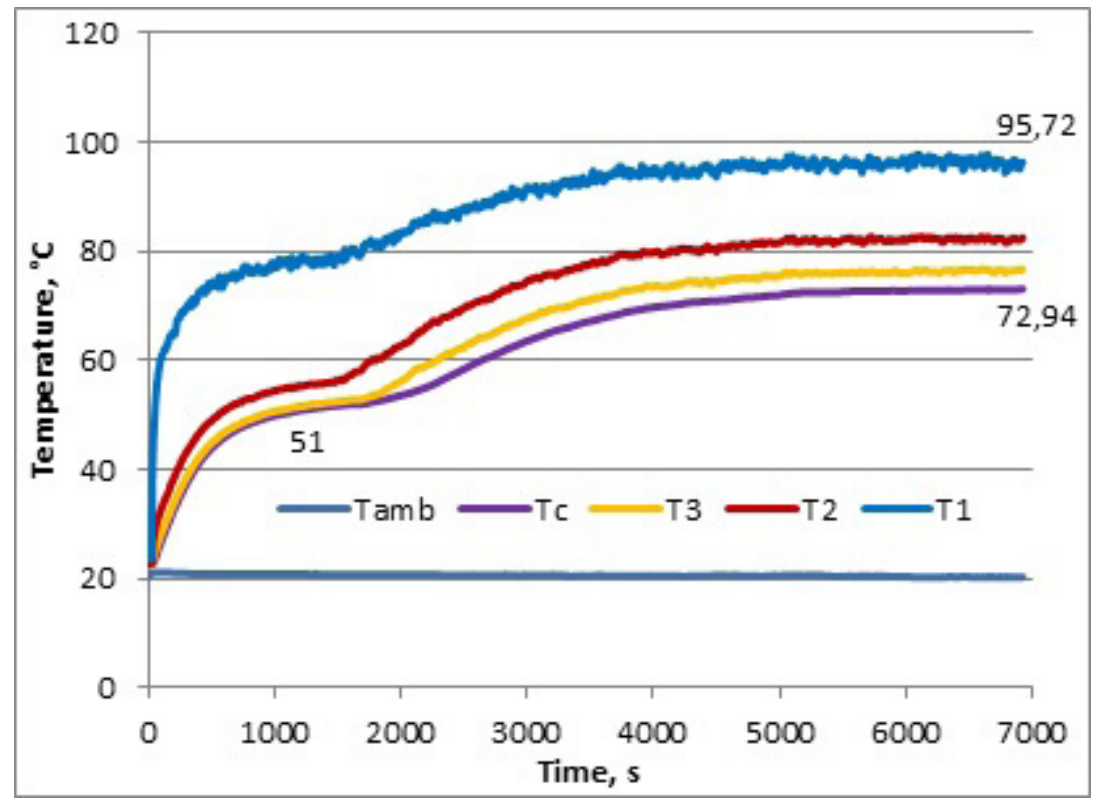

Figure 10. Temperatures between the layers (FJ1+UW); moisture content $160 \%$, located in the underwear; heat flux $1100 \mathrm{~W} / \mathrm{m}^{2}$

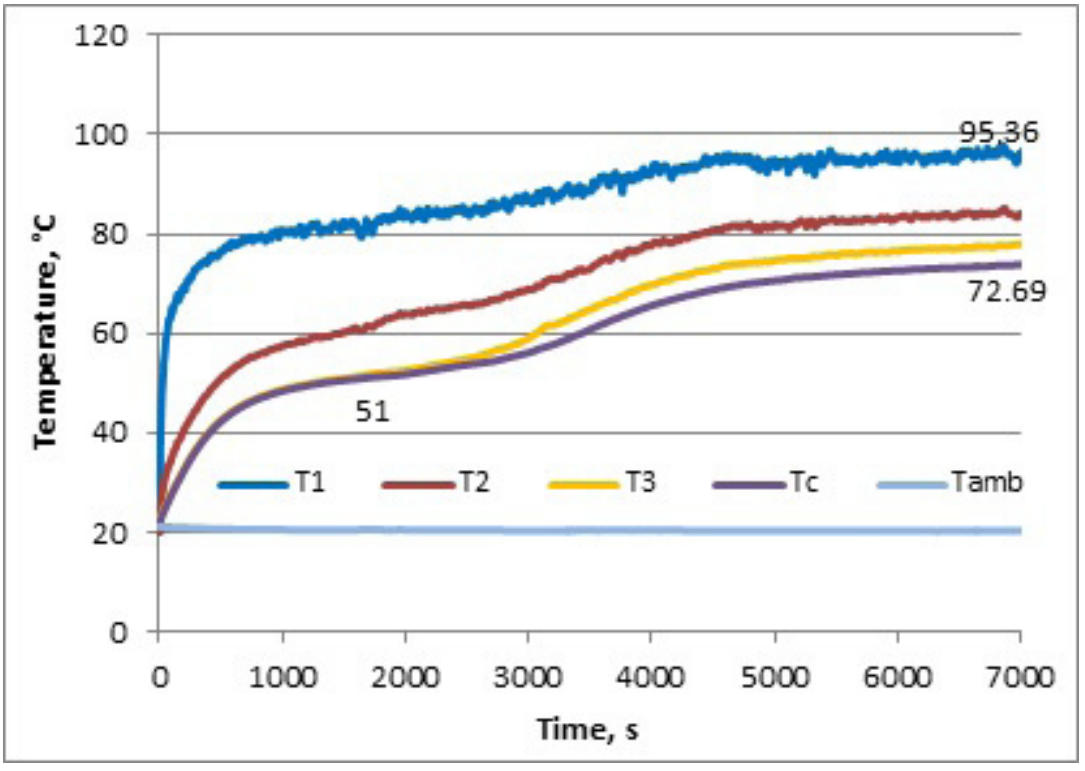

Figure 11. Temperatures between the layers (FJ1+UW); moisture content $200 \%$, located in the underwear; heat flux $1100 \mathrm{~W} / \mathrm{m}^{2}$ 
for a three-layer protective system + underwear, for $120 \%$, $160 \%$ and, respectively, $200 \%$ initial moisture content in the underwear layer.

Similar to the previous discussion, the temperature pattern can be divided into four different phases: an initial rising phase, a stagnation phase, a final rising phase and a final stagnation phase.

After the first stagnation phase, the temperature starts rising again and a steady-state condition is reached, indicating that the fabric is completely dry. The temperature at the back face stabilises at approximately $72{ }^{\circ} \mathrm{C}$ and the temperature $\mathrm{T} 1$ at about $95^{\circ} \mathrm{C}$. In fact, as soon as the moisture evaporates, the temperatures approach the temperatures measured for dry samples.

Figure 12 shows the comparison of the temperatures T1 and Tc, respectively, for different amounts of moisture content in underwear under a radiant heat flux of $1100 \mathrm{~W} / \mathrm{m}^{2}$. The moisture within the clothing assembly did not lead to increased temperatures compared with the measurements with dry samples. On the contrary, lower temperatures were reached during the evaporation process. This research demonstrates that moisture can positively affect the thermal protection of a clothing system.

The evaporation rates were $0.195 \mathrm{~g} / \mathrm{m}^{2} \mathrm{~s}$ for $200 \%$ moisture content, $0.183 \mathrm{~g} / \mathrm{m}^{2} \mathrm{~s}$ for $160 \%$ moisture content and 0.145 $\mathrm{g} / \mathrm{m}^{2} \mathrm{~s}$ for $120 \%$ moisture content, respectively. The time of evaporation was 1645 seconds for $120 \%$ moisture content, 2120 seconds for $160 \%$ moisture content and 2355 seconds for $200 \%$ moisture content. Thus, linear correlations were again confirmed between the moisture content and both the evaporation time and the evaporation rate.

For multi-layer clothing system the water-vapour resistance of the upper layers leads to a lower evaporation rate and consequently lower energy absorbed by evaporation. Thus, for the $\mathrm{FJ} 1+\mathrm{UW}$ tests, the temperature plateau is recorded at a higher value $\left(51^{\circ} \mathrm{C}\right)$ than for single underwear $\left(43.5^{\circ} \mathrm{C}\right)$.

The underwear containing $160 \%$ moisture was tested in combination with fire-fighter protective clothing consisting of four layers (FJ2) for three different heat flux densities: $1700 \mathrm{~W} /$ $\mathrm{m}^{2}, 1100 \mathrm{~W} / \mathrm{m}^{2}$ and $875 \mathrm{~W} / \mathrm{m}^{2}$. Figures 13,14 and 15 show the temperature variations.

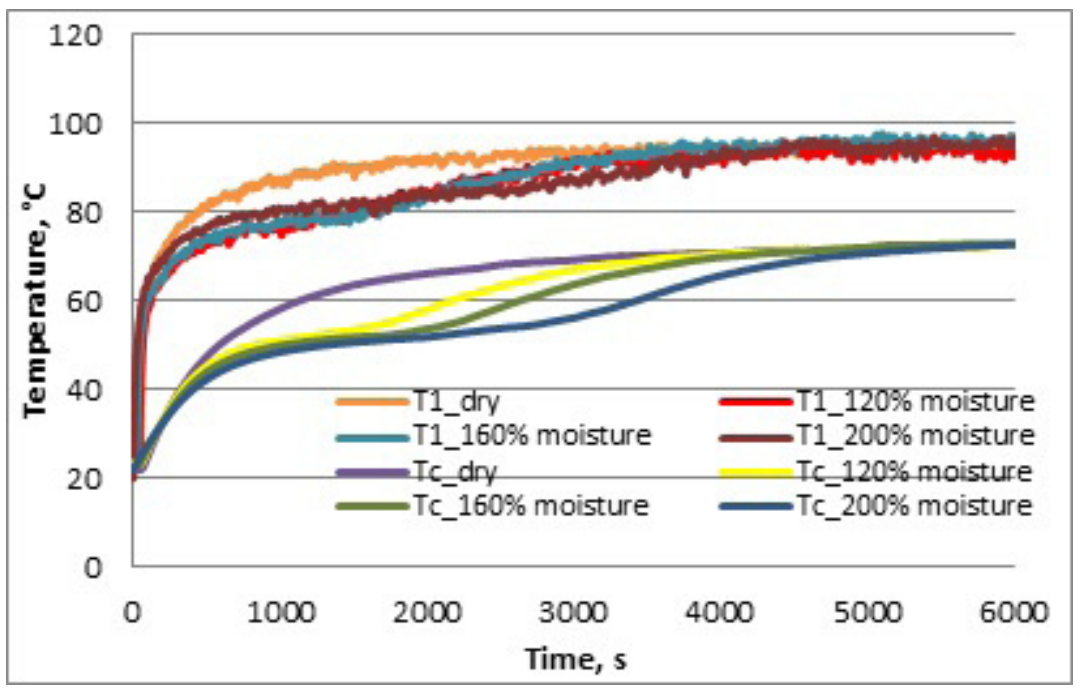

Figure 12. Comparison of the temperatures T1 and Tc, respectively, for different amounts of moisture content in underwear (FJ1+UW); heat flux $1100 \mathrm{~W} / \mathrm{m}^{2}$

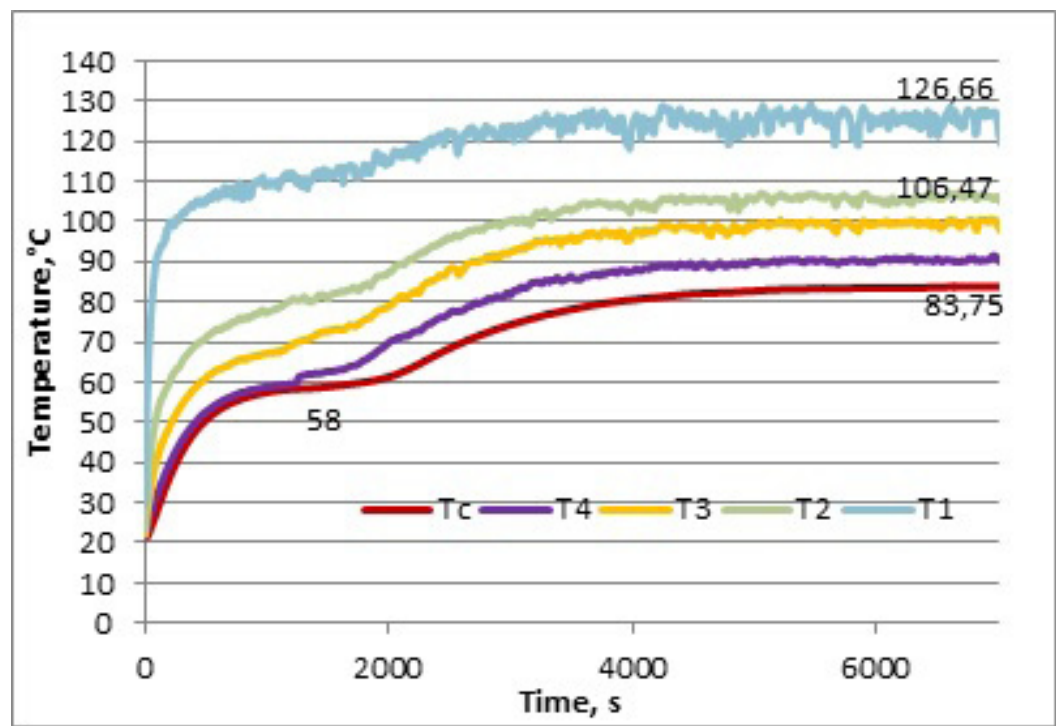

Figure 13. Temperatures between the layers (FJ2+UW); moisture content $160 \%$, located in the underwear; heat flux $1700 \mathrm{~W} / \mathrm{m}^{2}$ 


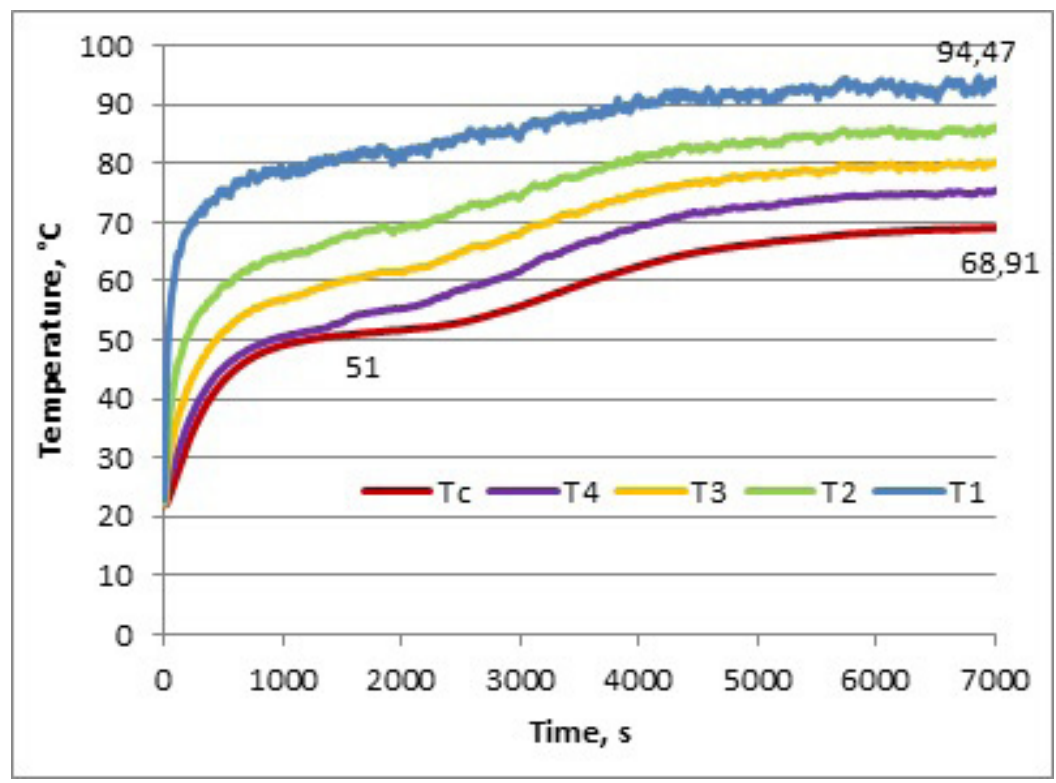

Figure 14. Temperatures between the layers (FJ2+UW); moisture content $160 \%$, located in the underwear; heat flux $1100 \mathrm{~W} / \mathrm{m}^{2}$

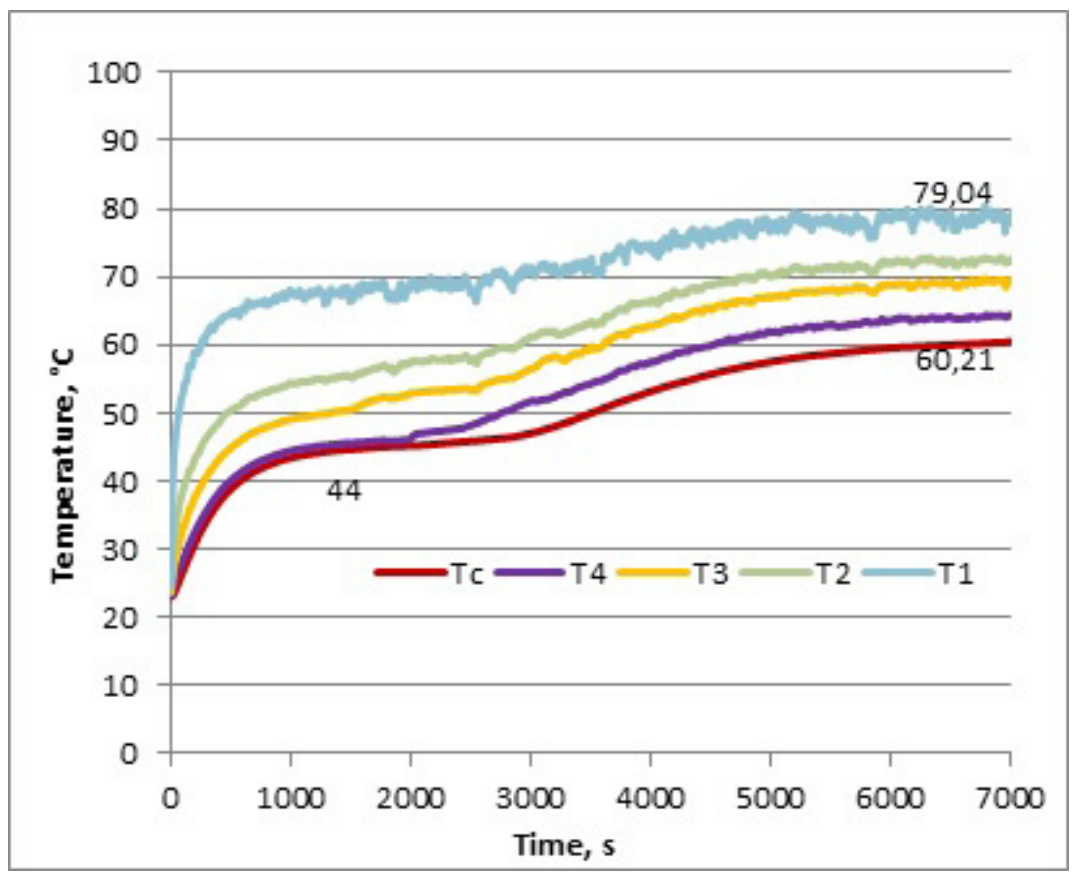

Figure 15. Temperatures between the layers (FJ2+UW); moisture content $160 \%$, located in the underwear; heat flux $875 \mathrm{~W} / \mathrm{m}^{2}$

In combination with FJ2 the evaporation rates were $0.223 \mathrm{~g} / \mathrm{m}^{2} \mathrm{~s}$ for the heat flux of $1700 \mathrm{~W} / \mathrm{m}^{2}, 0.170 \mathrm{~g} / \mathrm{m}^{2} \mathrm{~s}$ for the heat flux of $1100 \mathrm{~W} / \mathrm{m}^{2}$ and $0.150 \mathrm{~g} / \mathrm{m}^{2} \mathrm{~s}$ for the heat flux of $875 \mathrm{~W} / \mathrm{m}^{2}$, respectively. The time of evaporation was $2000 \mathrm{~s}$ for the heat flux of $1700 \mathrm{~W} / \mathrm{m}^{2}, 2610 \mathrm{~s}$ for the heat flux of $1100 \mathrm{~W} / \mathrm{m}^{2}$ and $3078 \mathrm{~s}$ for the heat flux of $875 \mathrm{~W} / \mathrm{m}^{2}$, respectively. Thus, linear correlations were confirmed between the heat flux density and both the second phase duration and the evaporation rate.

The evaporation temperature depends on the heat flux density: the higher the heat flux the higher the temperature at which the constant plateau is registered.

Even if the thermal resistance of FJ2 is lower than the thermal resistance of FJ1, comparable temperatures have been registered at steady state. This can be because of the fact that FJ2 has four layers, that is, one supplementary air gap between the textile layers compared with FJ1. This air gap can determine an increase of FJ2 thermal resistance.

On the contrary, for FJ1 with $34.9 \mathrm{~m}^{2} \mathrm{~Pa} / \mathrm{W}$ water-vapour resistance, the evaporation rate is $0.183 \mathrm{~g} / \mathrm{m}^{2} \mathrm{~s}$ and the evaporation time 2120 seconds. For FJ2 with $25.27 \mathrm{~m}^{2} \mathrm{~Pa} / \mathrm{W}$ water-vapour resistance, the evaporation rate is $0.170 \mathrm{~g} / \mathrm{m}^{2} \mathrm{~s}$ and the evaporation time 2660 seconds. This means that for the FJ1, with higher $R_{e t}$, the evaporation rate is higher and the time of evaporation is shorter. This is a contradiction that can be explained by the fact that barrier properties of hydrophilic membrane (component of FJ1) do depend on the applied watervapour pressure because of membrane swelling effect. Thus, the water-vapour resistance of hydrophilic membrane is reduced by increasing the water-vapour pressure applied to the sample, or, expressed in more simple terms, hydrophilic membrane responds to increasing water-vapour pressure by becoming 
more breathable [21, 22]. Following the presence of liquid water in the textile layers beneath the hydrophilic membrane, the vapour pressure under membrane gets close to the saturation pressure which results in an increase in the relative humidity and consequently a decrease in the water-vapour resistance.

\section{Conclusions}

We investigated simultaneous heat and moisture transfer through a single-layer fabric, used as underwear for firefighters, at different moisture conditions, when exposed to a low level of radiant heat. In the absence of a standardised method for testing the heat and moisture transfer through protective equipment for fire-fighters under routine conditions, a measuring device was developed, which was calibrated to deliver a constant radiant flux corresponding to these conditions of the fire-fighting environment.

The energy used for water evaporation was calculated from the evaporation rate and the energy balance equation, and a good correlation was found.

The underwear without additional water (dry condition) and with additional water was also tested together with two multi-layer fire-fighter jackets. In this experiment, moisture was applied before exposure to radiant heat.

During the evaporation of the moisture, a temperature plateau appeared during which temperatures were hardly rising. The energy consumption used for the phase change of moisture located in the assembly dominated the heat transfer process as long as there was moisture present. As soon as all water had evaporated, the temperatures approached the temperatures measured for dry samples.

Water has higher thermal conductivity relative to air and it has been assumed that heavily wet condition within the firefighter clothing makes faster temperature increase. But this research has confirmed that moisture can positively affect the thermal protection of a clothing system in case of routine firefighting operation. The moisture within the clothing assembly did not lead to increased temperatures compared with the measurements with dry samples. The effect of the higher heat capacity and energy absorption through vaporising overtook the effect of higher heat conductivity of the wet material.

Linear correlations were confirmed between the moisture content and both the evaporation time and the evaporation rate as well as between the heat flux density and both the evaporation time and the evaporation rate.

The evaporation temperature depends on the heat flux density: the higher the heat flux the higher the temperature at which the constant plateau is registered.

This study contributes to a better understanding of the impact of moisture retained in the underwear on the protective behaviour of overall fire-fighter clothing system, under the conditions of low-level radiant heat flux.

\section{Acknowledgements}

The authors gratefully acknowledge the region Nord-Pas-deCalais and the European Regional Development Fund for their financial support in the context of the research program FLUTEX.

\section{References}

[1] Song, G. (2011). Improving comfort in clothing. Woodhead Publishing Limited, Cambridge.

[2] Yoo, S., Barker, R.I. (2005). Comfort Properties of HeatResistant Protective Workwear in Varying Conditions of Physical Activity and Environment. Part I: Thermophysical and Sensorial Properties of Fabrics, Textile Research Journal, 75, 523.

[3] Durney, C.H., Massoudi, H., Iskander, M. F. (1986). Radiofrequency radiation dosimetry handbook. The University of Utah. Retrieved 30.05.2013 from Web site: http://www.radhaz.com/docs/RF\%20Dosimetry\%20 Handbook\%20ver\%204.pdf.

[4] Keiser, C. (2007). Steam burns. Moisture management in firefighter protective clothing. PhD Thesis, Swiss Federal Institute of Technology Zurich, Swiss.

[5] Schopper-Jochum, S., Schubert, W. and Hocke, M. (1997) Vergleichende Bewertung des Trageverhaltens von Feuerwehreinsatzjacken (Phase 1). Arbeitsmedizin, Sozialmedizin und Umweltmedizin, 32(4).

[6] Keiser, C. and Rossi, R.M. (2008). Temperature analysis for the prediction of steam formation and transfer in multilayer thermal protective clothing at low level thermal radiation. Textile Research Journal, 78 (11), 1025-1035.

[7] Mäkinen, H., Smolander, J., Vuorinen, H. (1988). Simulation of the effect of moisture content in underwear and on the skin surface on steam burns of firefighters. In: Mansdorf, S.Z., Sager, R., Nielsen, A.P., (eds). Performance of Protective Clothing: Issues and Priorities for the 21st Century, Second Symposium (ASTM STP 989). Philadelphia, PA, USA: American Society for Testing and Materials (ASTM), 415-421.

[8] Chen, N.Y. (1959). Transient Heat and Moisture Transfer to Skin through Thermally Irradiated Cloth. Doctoral Dissertation, Massachusetts Institute of Technology, Boston.

[9] Lee, Y.M., Barker, R.L. (1986). Effect of Moisture on the Thermal Properties of Heat-Resistant Fabrics. Journal of Fire Sciences, 4, 315-331.

[10] Rossi, R.M., Zimmerli, T. (1996). Influence of Humidity on the Radiant, Convective and Contact Heat Transmission through Protective Clothing Materials. In: Performance of Protective Clothing: Fifth Volume, ASTM STP 1237, James S. Johnson, J.S., Mansdorf, S. Z. (eds.) American Society for Testing and Materials, (ASTM), 269-280.

[11] Mäkinen, H. (2005) Firefighter's protective clothing. In: Scott RA (ed.) Textiles for Protection. Cambridge, Woodhead, UK, 622-647

[12] Song, G., Paskaluk, S., Sati, R. et al. (2011). Thermal protective performance of protective clothing used for low radiant heat protection, Textile Research Journal, 81(3), 311-323.

[13] Song, G., Gholamreza, F., Cao, W. (2011). Analyzing thermal stored energy and effect on protective performance, Textile Research Journal, 81(11), 1124-1138. 
[14] Fu,M., Wenguo Weng, W., Yuan, H. (2013) Effects of multiple air gaps on the thermal performance of firefighter protective clothing under low-level heat exposure, Textile Research Journal published online 12 December 2013. DOI: 10.1177/0040517513512403.

[15] Lawson, L.K., Crown, E.M., Ackerman, M.Y., Dale, J.D. (2004). Moisture Effects in Heat Transfer Through Clothing Systems for Wildland Firefighters. International Journal of Occupational Safety and Ergonomics (JOSE), 10(3), 227-238.

[16] Petrilli, T., Ackerman, M. (2008). Tests of Undergarments Exposed to Fire. Fire tech Tips. Retrieved 30.05.2013 from Web site http://www.fs.fed.us/t-d/pubs/pdfpubs/ pdf08512348/pdf08512348dpi72.pdf

[17]ISO 11092:1993 - Textiles - Physiological effects Measurement of thermal and water-vapour resistance under steady-state conditions (sweating guarded-hotplate test). ISO: Geneva, Switzerland
[18] Petrusic, S., Onofrei, E., Bedek, G., Dupont, D., Soulat, D. (2013). Investigation of Thermal Comfort Properties of Firefighter Protective Clothing. 4th ITMC Lille Metropole 2013 International Conference, ENSAIT, Roubaix, France.

[19] http://www.osram.fr/media/resource/hires/333561/ theratherm_siccatherm_infrared-en.pdf

[20] Kothandaraman, CP. (2006). Fundamental of heat and mass transfer. 3rd ed. New Delhi: New Age International (P) Limited, 608.

[21] Bartels, V. T. (2005). Physiological comfort of sportswear. In Textiles in Sports, Woodhead Publishing Limited, Cambridge.

[22] Nomax, G.R. (1990). Hydrophilic polyurethane coatings. Journal of Industrial Textiles, 20:88. DOI: $10.1177 / 152808379002000205$ 